\title{
RESEARCH
}

\section{Clinical features and outcomes of adrenal schwannoma: a study of 13 cases from a single centre}

\author{
Henghai Huang ${ }^{1, *}$, Qijian Ding ${ }^{2, *}$, Xiaocao Lin ${ }^{1}$, Delin Li', Jingjing Zeng ${ }^{3}$ and Weijin Fu \\ 'Department of Urology, Wuzhou GongRen Hospital, Wuzhou, China \\ 2Department of Urology, The First Affiliated Hospital of GuangXi Medical University, Nanning China \\ ${ }^{3}$ Department of Pathology, The First Affliated Hospital of GuangXi Medical University, Nanning, China
}

Correspondence should be addressed to W Fu: fuwj66@aliyun.com

${ }^{*}(\mathrm{H}$ Huang and Q Ding contributed equally to this work)

\begin{abstract}
Background: Adrenal schwannomas (AS) are extremely rare neoplasms. This study shares our experience regarding the diagnosis and operative management of AS.

Methods: Clinical details, radiologic, laboratory, and pathologic findings as well as

follow-up data were analysed retrospectively for 13 AS patients who accepted surgery at a tertiary referral hospital in China between 1 January 1996, and 31 December 2017. Results: The mean age of the patients at diagnosis was $44.7 \pm 13.7$ years (range 19-62 years; male: female ratio, 1:1.16), of whom seven patients had unilateral AS on the right side, and the remaining six on the left side. None of the cases were hormonally active. None of the 13 cases were diagnosed as AS by CT imaging before the operation. Among the patients, ten were asymptomatic. The mean preoperative size was $7.1 \pm$ $3.2 \mathrm{~cm}$ (range 1.6-12.6 cm). All patients underwent surgery, with open adrenalectomy in five patients and laparoscopy in eight patients. The mean tumor size on pathologic examination was $6.8 \pm 3.0 \mathrm{~cm}$ (range 3.0-11.7 cm). The surgical specimens were confirmed by pathological examination. During a median follow-up of $60.8 \pm 17.7$ months, no patients showed recurrence or metastasis.

Conclusion: The preoperative diagnosis of AS remains difficult despite the advances in imaging examinations. After complete resection, the prognosis of AS is excellent.
\end{abstract}

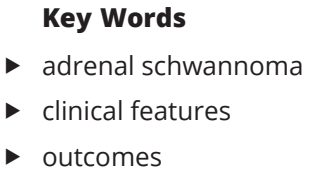

Endocrine Connections (2021) 10, 543-549

\section{Introduction}

Schwannoma is a rare tumour arising from Schwann cells in the myelinated neural sheath of the nerves (1). Tumours can occur in various places, such as the head, neck, extremities, retroperitoneum, and psoas muscle (2, $3)$. Related studies have shown that approximately $5 \%$ of schwannoma cases come from the retroperitoneum (4). However, schwannomas presenting in the visceral organs, especially the adrenal glands, are rare $(5,6)$. The adrenal medulla is innervated by the phrenic nerve, the vagus nerve and the sympathetic trunk. Adrenal schwannoma (AS) arises from Schwann cells related to these nerves
$(7,8)$. AS is usually benign and slow-growing but can be malignant (9). AS is mostly asymptomatic, but some patients can present with either abdominal or flank pain. AS has a good prognosis after surgical excision.

Due to its low incidence, only a few case reports and small case series have been published to date (10). Thus, a comprehensive understanding of the clinical features, diagnosis, and clinical treatment of AS is necessary. In this study, we present our experiences regarding the clinical features, diagnostic imaging, and operative treatment of 13 AS cases in a single institution.

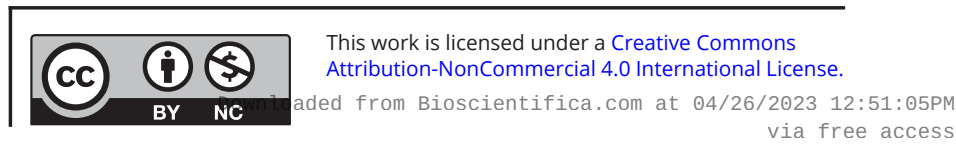




\section{Subjects and methods}

A total of 548 patients with adrenal neoplasms were treated at Wuzhou GongRen Hospital between 1 January 1996, and 31 December 2016. Of these, $13(2.37 \%, 13 / 548)$ were pathologically diagnosed with AS. The clinicopathological features, diagnosis, surgical intervention and follow-up data of these patients were retrospectively analysed. This study was approved by the Ethics Committee of Wuzhou GongRen Hospital.

All patient demographic parameters, chief complaints, concomitant diseases and operative histories were analysed. All patients were assessed for adrenal function, including (i) serum potassium; (ii) plasma adrenocorticotropic hormone and cortisol (08:00, 16:00 and 12:00 h); (iii) 24-h urinary free cortisol; (iv) plasma renin and aldosterone (standing and lying position); (v) 24-h urinary epinephrine, norepinephrine, dopamine and vanillylmandelic acid; (vi) serum epinephrine, norepinephrine and dopamine and (vii) serum testosterone and oestrogen.

All patients were evaluated by ultrasound and enhanced CT. The precontrast and postcontrast Hounsfield units (HU), maximum diameter, characteristics and preoperative diagnosis were analysed.

The surgical specimens were confirmed by pathological examination. The resection margins and pathological diagnosis were evaluated by two pathologists specialized in genitourinary diseases. The routine follow-up schedule was every 3 months in the 1st year after surgery, every 6 months in the 2nd year postoperatively, and once each year in the future.

\section{Results}

Table 1 summarizes the essential demographiccharacteristics and clinical presentations of the 13 AS patients. Their mean

Table 1 Patients' demographic and clinical characteristics.

\begin{tabular}{|c|c|}
\hline Patients & $\boldsymbol{n}(\%)$ \\
\hline Age, median (range) & $44.7(19-62)$ \\
\hline \multicolumn{2}{|l|}{ Gender } \\
\hline Female & $7(7 / 13)$ \\
\hline Male & $6(6 / 13)$ \\
\hline \multicolumn{2}{|l|}{ Clinical presentations } \\
\hline Incidental & $10(10 / 13)$ \\
\hline Abdominal/back discomfort & $2(2 / 13)$ \\
\hline Dizziness & $1(1 / 13)$ \\
\hline \multicolumn{2}{|l|}{ Tumor site } \\
\hline Right & $7(7 / 13)$ \\
\hline Left & $6(6 / 13)$ \\
\hline Mean preoperative tumor size in $\mathrm{cm}$ (range) & $7.1(1.6-12.6)$ \\
\hline Mean tumor size in $\mathrm{cm}$ on pathology (range) & $6.8(3.0-11.7)$ \\
\hline $\begin{array}{l}\text { https://ec.bioscientifica.com } \\
\text { https://doi.org/10.1530/EC-21-0062 }\end{array}$ & $\begin{array}{l}\text { (c) } 2021 \text { The authors } \\
\text { ed by Bioscientifica Ltd }\end{array}$ \\
\hline
\end{tabular}

age was $44.7 \pm 13.7$ years (range, 19-62 years), including six patients with tumours on the left and seven on the right. Ten cases were detected incidentally; two patients presented with abdominal or back discomfort, and one patient presented with dizziness. Table 1 summarizes their demographic characteristics and clinical manifestations. Preoperative endocrine function examinations and serum potassium levels were normal in Table 2 . A routine medical examination was the main indicator $(10 / 13 ; 76.9 \%)$ of clinical signs leading to the discovery of an AS.

All of the adrenal masses were unilateral. Ultrasonography was performed in 13 patients but showed no specificity. The masses showed solid or mixed echoes. Blood flow signals could be observed in the tumours, and the masses were hypoechoic, with regular morphology and clear boundaries. A small amount of blood flow was observed within or around the lesions.

In our study, CT findings were available for 13 patients. Table 3 summarizes the clinical and CT findings of the 13 AS patients. Six tumours were located on the left adrenal gland, and the remaining seven were on the right side. The tumour diameters ranged from approximately 1.6 to $12.6 \mathrm{~cm}$ (mean $7.1 \pm 3.2 \mathrm{~cm}$ ). All tumours were unilateral, heterogeneous, round or oval solitary encapsulated masses and thus presented with well-circumscribed margins in the unenhanced phase (Figs 1, 2 and 3). Intratumoural cystic changes were observed in six cases (46.2\%, Fig. $1)$, calcification was observed in one case (7.7\%, Fig. 2), and septa were observed in three cases (23\%, Fig. 3). Haemorrhage was not observed in any of the cases.

On the multiphase CT images, all solid areas displayed an early mild heterogeneous enhancement in the hepatic arterial phase and a delayed progressive enhancement in the portal venous and equilibrium phases. There were no malignant features, such as invasion of the adjacent tissues, regional lymph node involvement, or distant metastasis. None of the 13 patients were diagnosed with AS by CT imaging before their operation. The preoperative radiologic studies suggested that five were inconclusive, one was considered to be malignant ('adrenal carcinoma' or 'liposarcoma'), four were considered to be pheochromocytomas, two were considered to be cortical adenomas, and one was considered to be a cyst. A retrospective review revealed that tumour density was heterogeneous with low attenuation in 12 patients and homogeneous in 1 patient, as shown in the precontrast CT images. Slight, early enhancement was seen in the postcontrast images in all of the patients.

All of the AS patients underwent operative resection by open adrenalectomy (five patients) and laparoscopy

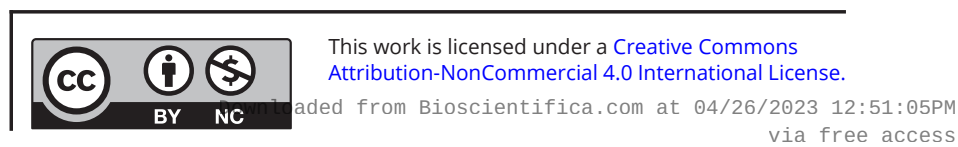




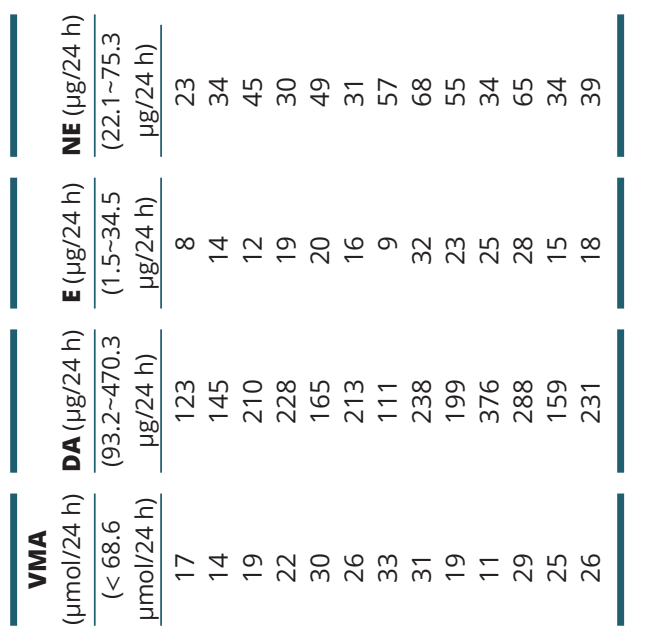

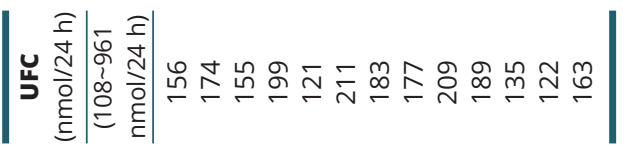

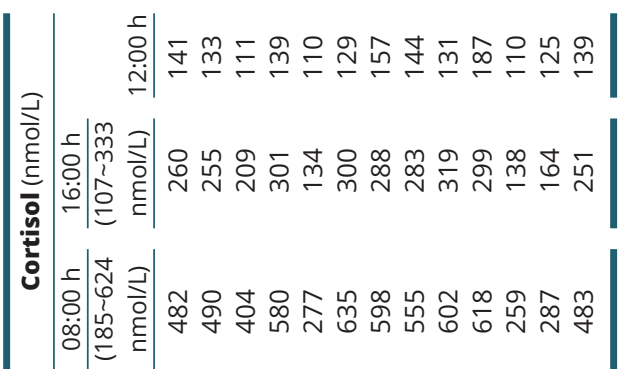

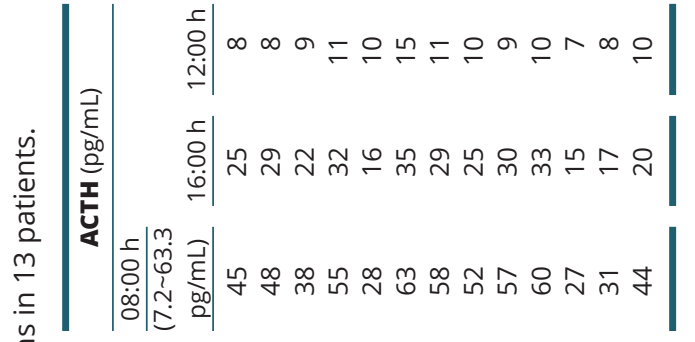

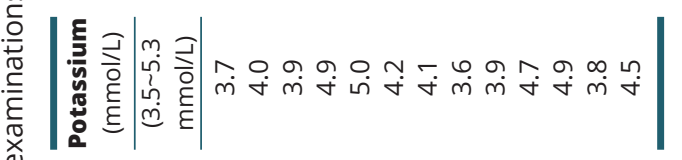

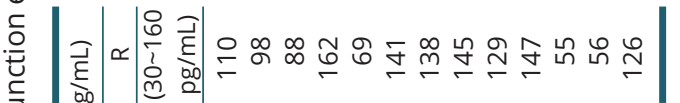
:

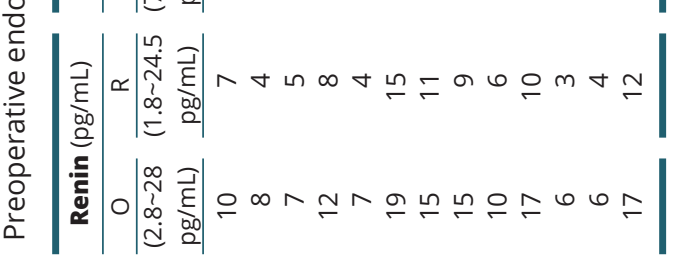

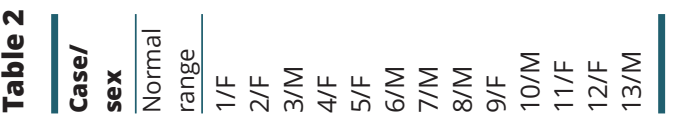

(the remaining eight patients). Surgical indications were $\geq 1$ of each of the following: tumour size $\geq 4 \mathrm{~cm}$ $(n=11)$, suspicious appearance on imaging $(n=5)$, or a patient's fear of malignancy $(n=9)$.

The mean tumour size on pathologic examination was $6.8 \pm 3.0 \mathrm{~cm}$ (range 3.0-11.7 cm). The tumour was typically well-circumscribed as an encapsulated round (Fig. 4A) or lobulated mass (Fig. 4C). The cut surface often consisted of firm yellow-tan tissue (Fig. 4B) or contained cystic or solid regions (Fig. 4D). All 13 patients were diagnosed with AS by pathology. Microscopic examination showed that the tumour consisted of alternating hypercellular (Antoni type A tissue) and hypocellular areas (Antoni type B tissue) (Fig. 5A and B). Immunohistochemical staining showed a diffuse expression of S-100 protein (Fig. 5C) and positive immunoreactivity for vimentin (Fig. 5D) in the tumour cells. These findings are consistent with a diagnosis of benign AS.

There was no mortality, minor morbidity or complication in our patients. During a median follow-up of $60.8 \pm 17.7$ months (range 39-92 months), no patient had recurrence or metastasis.

\section{Discussion}

AS is a rare incidentaloma found in the adrenal medulla, and fewer than 100 cases have been reported to date $(6,10,11,12,13,14,15,16,17,18)$. The vast majority of AS patients are sporadic. The specific cause of the disease is unknown. Genomic analysis demonstrated that there were neurofibromatosis type 2(NF2) alterations in intracranial and spinal schwannoma, which may be related to chromosome $22 \mathrm{q}$ and NF2 mutations. The chromatin-modifying genes ARID1A or ARID1B, as well as mutations in DDR1 were found in intracranial and spinal schwannoma $(19,20)$. However, it remains to be investigated whether similar genetic changes also exist in AS patients. The ratio of female to male patients is approximately 1.2:1, and the mean age of onset is 49 years (6). In this study, the ratio of female to male patients was approximately 1.16:1, and the mean age was 44.7 years, which is consistent with the literatures. Furthermore, the majority of cases were likely isolated; therefore, the true incidence of AS in patients undergoing adrenalectomy remains unknown. In this study, the incidence of AS among these patients was 2.37\% (13/548) at our institution.

Owing to the lack of endocrine function, most cases of AS do not cause any corresponding clinical symptoms.

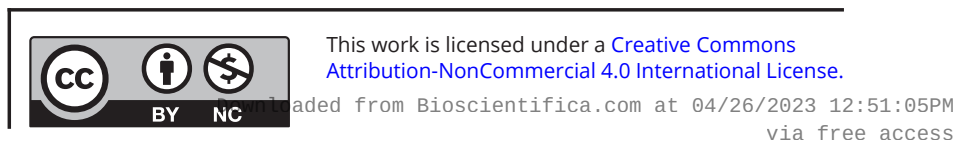



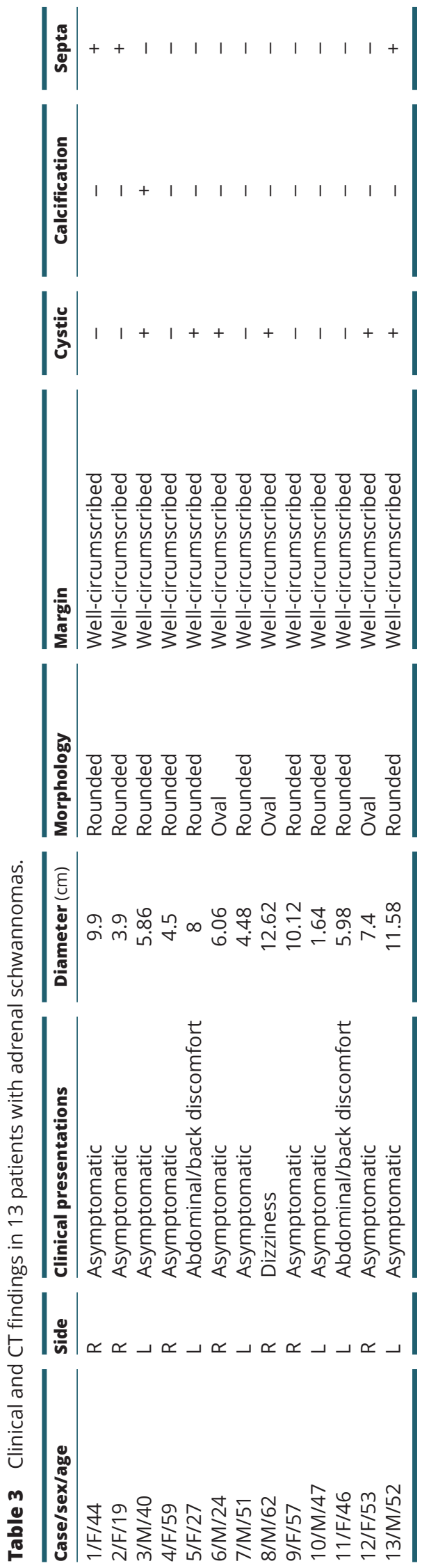

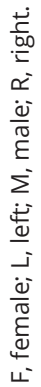

https://ec.bioscientifica.com https://doi.org/10.1530/EC-21-0062

(c) 2021 The authors Published by Bioscientifica Ltd
The majority of our patients had no clinical symptoms. In the present study, 10 out of 13 AS cases were incidental tumours. They were diagnosed with adrenal lesions while imaging for other diseases. Some patients suffer from abdominal pain and abdominal distention due to increased tumour sizes. The literature indicates that AS ranges in size from 0.6 to $14.5 \mathrm{~cm}$, with a median of 5.5 $\mathrm{cm}$ (6). The mean tumour size in our study was $6.8 \mathrm{~cm}$, which is larger than that reported in the literature and is possibly related to the late presentation of the patients to our institution.

It is difficult to diagnose AS before surgery. Imaging findings have some significance for AS diagnosis. The literature has suggested that the following signs may support the diagnosis of this entity: a nonlipid-containing mass, a well-defined border, a unilateral mass with cystic or haemorrhagic degeneration, septa with delayed enhancement and a characteristic progressive contrast enhancement pattern of the solid portions (21).

The final diagnosis of AS depends on histopathology. The typical features are as follows: (i) in gross specimens, the lesion size varies, with a round or nodular contour, with a tan-yellow to greyish-white appearance and integrated capsule, the colour of cross sections is pink or brownish-grey and slightly transparent, with a solid and rough texture and a spiral structure, and focal jelly like necrosis is visible in some specimens; (ii) by HE staining, spindle cells can be found and may be complicated by haemorrhage, cystic, and hyaline degeneration. In light of the cell arrangement, pathology can be classified as
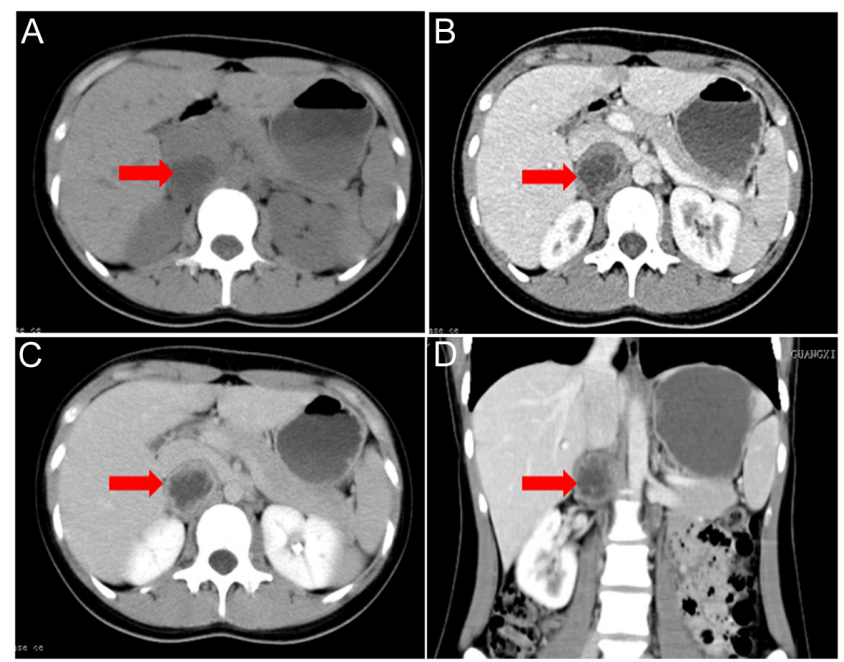

Figure 1

Unenhanced phase (A), hepatic arterial phase (B), portal venous phase (C) and coronal CT (D). CT imaging reveals a well-circumscribed mixed solid cystic mass (red arrow) located in the region of the right adrenal gland.

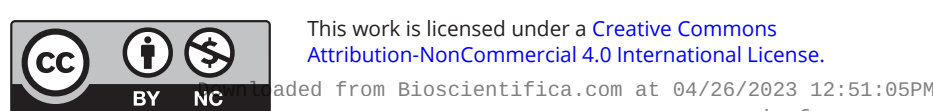



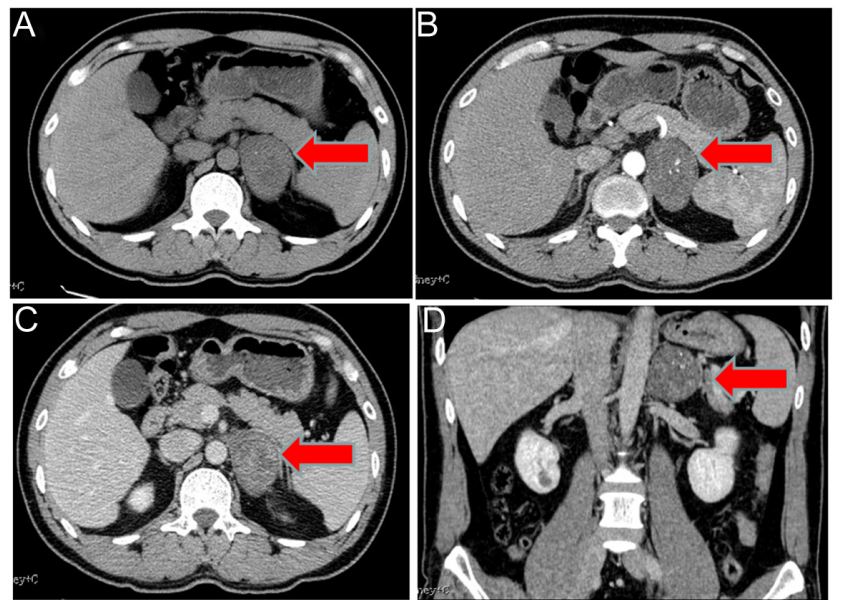

Figure 2

Unenhanced phase (A), hepatic arterial phase (B), portal venous phase (C) and coronal CT (D). CT imaging reveals a well-circumscribed,

heterogeneous mass with calcification (red arrow) located in the region of the left adrenal gland.

either Antoni A or Antoni B. Antoni A-type tumours show spindle cells arranged in a dense (hypercellular) manner with ill-defined intercellular spaces, and Antoni B-type tumour cells are arranged in a loose (hypocellular) manner with large intercellular spaces and a high degree of myxoid degeneration and (iii) by immunohistochemistry, specimens are always positive for the expression of S-100, Leu7, laminin, and myelin basic protein. Tumour cells can express CD34, glial fibrillary acidic protein, and cytokeratins but not epithelial membrane antigen (EMA), desmin, or actin (16). Haemorrhage, necrosis, and cystic and hyaline degeneration are thought to be indicative of
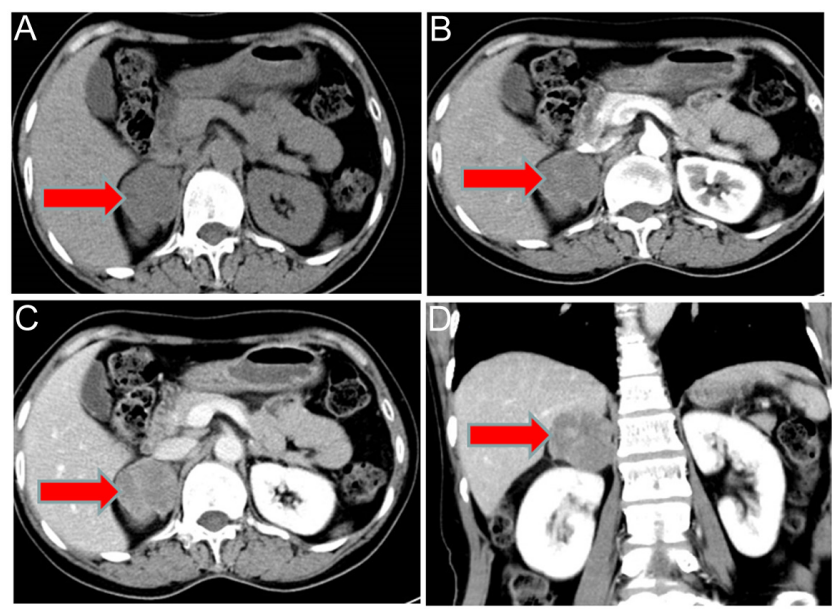

Figure 3

Unenhanced phase (A), hepatic arterial phase (B), portal venous phase (C) and coronal CT (D). CT imaging reveals a well-circumscribed,

heterogeneous mass with septa (red arrow) located in the region of the left adrenal gland.

https://ec.bioscientifica.com https://doi.org/10.1530/EC-21-0062

(c) 2021 The authors Published by Bioscientifica Ltd
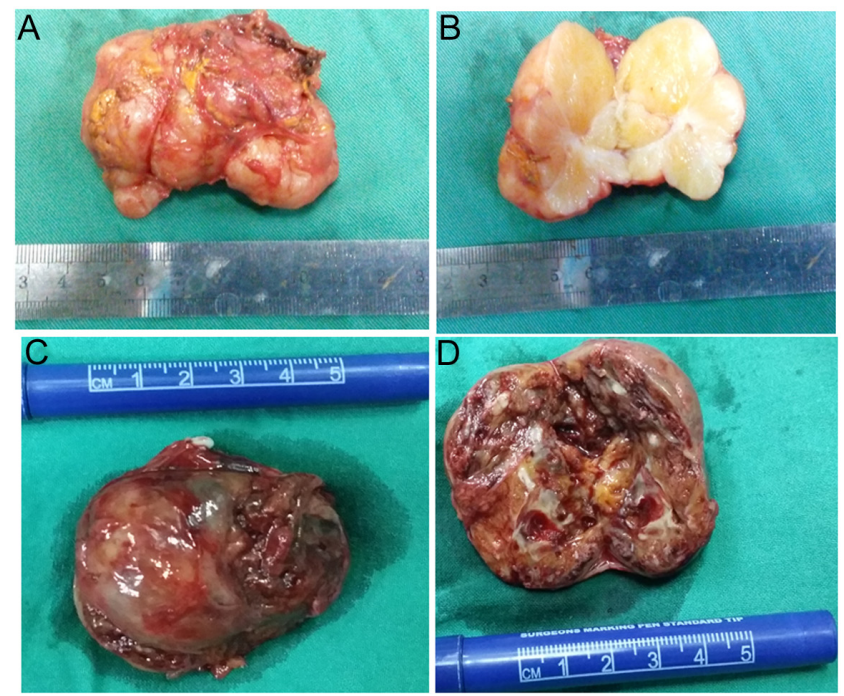

\section{Figure 4}

Gross specimen showing that the tumour is typically well circumscribed as an encapsulated round (A) or lobulated mass (C). The cut surface often consists of firm yellow-tan tissue (B) or contains areas of cyst-solid formation (D).

malignancy potential due to vascular insufficiency caused by increasing tumour size.

Most cases of AS have no endocrine function. However, a few studies have reported that AS may be accompanied by excessive secretion of corticosteroids or adrenomedullary hormones (9). It has been suggested that a routine examination of adrenal endocrine function be performed before surgery to determine the nature of the incidental adrenal tumours, to determine whether there is endocrine function and to select appropriate treatment methods.

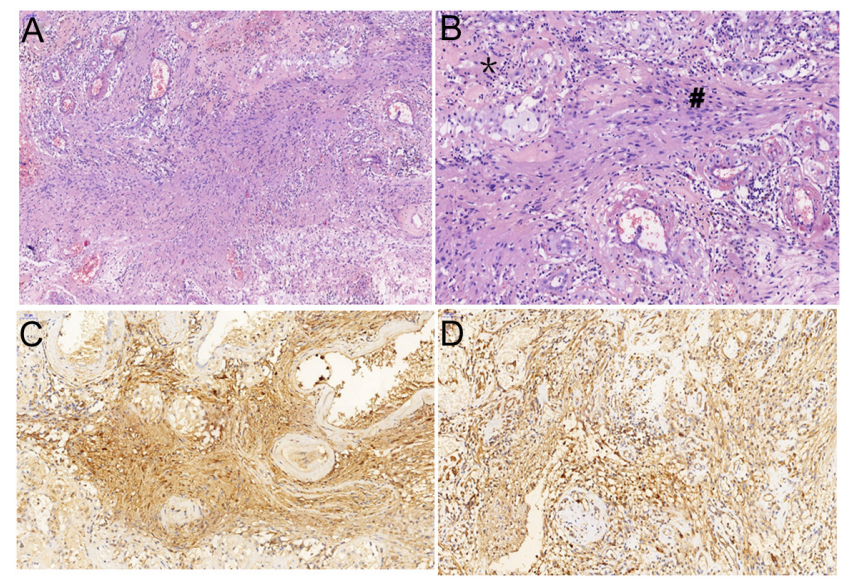

\section{Figure 5}

Microscopic examination showing that the tumour consists of compact or loose interlacing fascicles of bland spindle cells $(A, \times 100)$. Antoni $A$ areas $(\#)$ and loose myxoid degenerative Antoni $B$ areas $\left({ }^{*}\right)$ are noted $(B, \times 200)$. Immunohistochemical staining demonstrates that the tumour is positive for S-100 protein (C) and vimentin (D).

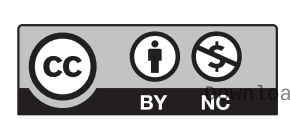

This work is licensed under a Creative Commons Attribution-NonCommercial 4.0 International License. ded from Bioscientifica.com at 04/26/2023 12:51:05PM 
The treatment of adrenal incidentaloma depends on its endocrine function and whether the tumour is benign or malignant, and it must take into account the patient's general condition and wishes. For nonfunctional adrenal incidentalomas, there is a disagreement on management. At present, the literature holds that when the diameter of the tumour is $>4 \mathrm{~cm}$, the risk of malignancy increases and the risk of malignancy is $>25 \%$ for tumours $>6 \mathrm{~cm}$; thus, active surgical treatment is advocated. Follow-up is recommended for tumours $<4 \mathrm{~cm}$. Surgical intervention is also recommended for tumours with rapid growth, inhomogeneity, an irregular shape, necrosis and invasion of adjacent structures, which may indicate malignant tumours $(22,23,24)$.

Surgical resection is the most effective treatment for AS. Laparoscopic adrenalectomy is considered the gold standard technique for the treatment of benign smalland medium-sized adrenal masses $(<6 \mathrm{~cm})$ due to its low morbidity rate, short hospitalization and rapid patient recovery $(25,26,27)$. With the development of more advanced laparoscopic equipment and technology, it has been reported that large tumours $(>10 \mathrm{~cm})$ have been successfully removed by laparoscopic surgery (28). Due to magnification, laparoscopic surgery requires less space, is much clearer and is more precise. A large tumour diameter is not a contraindication for laparoscopic surgery. Most Chinese urologists prefer retroperitoneal laparoscopic adrenalectomy to treat adrenal tumours (tumour size $<6 \mathrm{~cm}$ ). However, as the size of the adrenal tumour increases, the technical difficulty increases, and there is an increased risk of dealing with malignant gland pathology. Therefore, open surgery may be a good choice for patients with tumour sizes $>6 \mathrm{~cm}$. Specific operation patterns are performed according to the patient's situation and the surgeon's preference and technical expertise. In the present study, eight patients underwent retroperitoneal laparoscopic adrenalectomy (the tumour diameter of these eight cases was $<6 \mathrm{~cm}$ ). Open surgery was performed in five patients with tumour sizes $>6 \mathrm{~cm}$.

It should be pointed out that if the preoperative tumor volume is large and malignancy is suspected before surgery. Open surgery should still be considered the standard surgical management of adrenal malignancy. Laparoscopic surgery can offer a shorter hospital stay and possibly a faster recovery. Therefore, this minimally invasive approach can certainly play an important role in this setting, but it should be only offered in carefully selected cases, and performed by skilled experts, to afford a better oncological outcome $(29,30)$. Either open surgery or laparoscopic surgery should be chosen to avoid damaging the tumour capsule to cause tumour implantation metastasis. At that time, open surgery should be the best choice.

All patients were discharged without complications postoperatively. All patients were followed-up for a mean of $60.8 \pm 17.7$ months (range 39-92 months) without recurrence or metastasis. AS has a good prognosis. Although the majority of the literatures consider this disease to be benign, and our findings also confirm this. The pathogenesis of AS need to be further investigated. Herein, we still recommend routine follow-up schedules as described above after surgery.

In conclusion, due to its rarity, AS is discovered mainly during routine medical check-ups. The preoperative diagnosis of AS remains difficult. After complete resection, the prognosis of AS patients is excellent.

\section{Declaration of interest}

The authors declare that there is no conflict of interest that could be perceived as prejudicing the impartiality of the research reported.

\section{Funding}

This work did not receive any specific grant from any funding agency in the public, commercial, or not-for-profit sector.

\section{References}

1 Ben Moualli S, Hajri M, Ben Amna M, Kolsi K, Chebil M, Ben Jilani S, Zaouech A \& Ayed M. Retroperitoneal schwannoma. Case report. Annales d'Urologie 200135 270-272. (https://doi.org/10.1016/s00034401(01)00042-0)

2 Daneshmand S, Youssefzadeh D, Chamie K, Boswell W, Wu N, Stein JP, Boyd S \& Skinner DG. Benign retroperitoneal schwannoma: a case series and review of the literature. Urology 200362 993-997. (https://doi.org/10.1016/s0090-4295(03)00792-1)

3 Rha SE, Byun JY, Jung SE, Chun HJ, Lee HG \& Lee JM. Neurogenic tumors in the abdomen: tumor types and imaging characteristics. Radiographics 200323 29-43. (https://doi.org/10.1148/rg.231025050)

4 Kasperlik-Zaluska AA, Roslonowska E, Slowinska-Srzednicka J, Otto M, Cichocki A, Cwikla J, Slapa R \& Eisenhofer G. 1,111 patients with adrenal incidentalomas observed at a single endocrinological center: incidence of chromaffin tumors. Annals of the New York Academy of Sciences $2006 \mathbf{1 0 7 3}$ 38-46. (https://doi.org/10.1196/ annals.1353.004)

5 Toutouzas KG, Tsamis D, Kekis PB, Michalopoulos NV, Flessas I, Manouras A, Zografos G \& Geogrios Z. Laparoscopic resection of an adrenal schwannoma. JSLS 201216 663-667. (https://doi.org/10.429 3/108680812X13517013316753)

6 Mohiuddin Y \& Gilliland MG. Adrenal schwannoma: a rare type of adrenal incidentaloma. Archives of Pathology and Laboratory Medicine 2013137 1009-1014. (https://doi.org/10.5858/arpa.2012-0291-RS)

7 Korets R, Berkenblit R \& Ghavamian R. Incidentally discovered adrenal schwannoma. JSLS 200711 113-115.

8 Lau SK, Spagnolo DV \& Weiss LM. Schwannoma of the adrenal gland: report incidentally discovered adrenal schwannoma of two cases. American Journal of Surgical Pathology 200630 630-634. (https://doi.org/10.1097/01.pas.0000194739.80174.26) 
9 Hou J, Zhang L, Guo Y, Chen H \& Wang W. Primary adrenal schwannoma with catecholamine hypersecretion. Archives of Medical Science 201612 681-683. (https://doi.org/10.5114/aoms.2016.59942)

10 Kumar S, Karthikeyan VS, Manohar CS, Sreelakshmi K \& Shivalingaiah M. Adrenal schwannoma: a rare incidentaloma. Journal of Clinical and Diagnostic Research 201610 PD01-PD02. (https://doi. org/10.7860/JCDR/2016/20405.8265)

11 Abdessater M, El Mokdad M, Gas J, Sleiman W, Coloby P \& Bart S. Juxta-adrenal schwannoma presenting as a giant adrenal tumor: a case report and a literature review. International Journal of Surgery Case Reports 201853 132-136. (https://doi.org/10.1016/j. ijscr.2018.10.017)

12 Shivalingaiah PH, Kumar P \& Bajoria S. Adrenal schwannoma treated with open adrenalectomy: a case report. Indian Journal of Surgical Oncology 20189 83-85. (https://doi.org/10.1007/s13193-017-0715-5)

13 Bhattar R, Tomar V, Dhakad DS \& Agarwal N. Benign diaphragmatic neurilemmoma mimicking a left adrenal cyst. Turkish Journal of Urology 201844 87-90. (https://doi.org/10.5152/tud.2017.26780)

14 Babaya N, Makutani Y, Noso S, Hiromine Y, Ito H, Taketomo Y, Ueda K, Ushijima H, Komoike Y, Yamazaki Y, et al. Case report: schwannoma arising from the unilateral adrenal area with bilateral hyperaldosteronism. BMC Endocrine Disorders 201717 74. (https:// doi.org/10.1186/s12902-017-0225-z)

15 Cayirli H, Tanriverdi HI, Ozguven AA, Gunsar C, Ersoy B \& Kandiloglu AR. Schwannoma localized retroperitoneally in a 14-yearold boy. Case Reports in Pediatrics 20162016 1210874. (https://doi. org/10.1155/2016/1210874)

16 Li SQ, Zhang YS, Shi J \& Li HZ. Clinical features and retroperitoneal laparoscopic resection of adrenal schwannoma in 19 patients. Endocrine Practice 201521 323-329. (https://doi.org/10.4158/ EP14453.OR)

17 Zhou W, Zhu Y, Zhang L, Xu SY \& Zhan WW. Sonographic appearances of adrenal schwannomas. Journal of Clinical Ultrasound 201947 3-8. (https://doi.org/10.1002/jcu.22644)

18 Xiao C, Xu B, Ye H, Yang Q, Wang L \& Sun YH. Experience with adrenal schwannoma in a Chinese population of six patients. Journal of Endocrinological Investigation 201134 417-421. (https://doi. org/10.1007/BF03346705)

19 Havik AL, Bruland O, Myrseth E, Miletic H, Aarhus M, Knappskog PM \& Lund-Johansen M. Genetic landscape of sporadic vestibular schwannoma. Journal of Neurosurgery $2018128911-922$. (https://doi.org/10.3171/2016.10.JNS161384)

20 Agnihotri S, Jalali S, Wilson MR, Danesh A, Li M, Klironomos G, Krieger JR, Mansouri A, Khan O, Mamatjan Y, et al. The genomic landscape of schwannoma. Nature Genetics 2016 48 1339-1348. (https://doi.org/10.1038/ng.3688)

21 Tang W, Yu XR, Zhou LP, Gao HB, Wang QF \& Peng WJ. Adrenal schwannoma: CT, MR manifestations and pathological correlation. Clinical Hemorheology and Microcirculation 201868 401-412. (https:// doi.org/10.3233/CH-170316)

22 Lau J, Balk E, Rothberg M, Ioannidis JP, DeVine D, Chew P, Kupelnick B \& Miller K. Management of clinically inapparent adrenal mass. Evidence Reports/Technology Assessments 200256 1-5. (available at:https://www.ncbi.nlm.nih.gov/books/NBK36558/)

23 Mansmann G, Lau J, Balk E, Rothberg M, Miyachi Y \& Bornstein SR. The clinically inapparent adrenal mass: update in diagnosis and management. Endocrine Reviews 200425 309-340. (https://doi. org/10.1210/er.2002-0031)

24 Anagnostis P, Karagiannis A, Tziomalos K, Kakafika AI, Athyros VG \& Mikhailidis DP. Adrenal incidentaloma: a diagnostic challenge. Hormones 20098 163-184. (https://doi.org/10.14310/ horm.2002.1233)

25 Erbil Y, Barbaros U, Karaman G, Bozbora A \& Ozarmagan S. The change in the principle of performing laparoscopic adrenalectomy from small to large masses. International Journal of Surgery 20097 266-271. (https://doi.org/10.1016/j.ijsu.2009.04.011)

26 Agrusa A, Romano G, Frazzetta G, Chianetta D, Sorce V, Di Buono G \& Gulotta G. Laparoscopic adrenalectomy for large adrenal masses: single team experience. International Journal of Surgery 201412 (Supplement 1) S72-S74. (https://doi.org/10.1016/j.ijsu.2014.05.050)

27 Conzo G, Gambardella C, Candela G, Sanguinetti A, Polistena A, Clarizia G, Patrone R, Di Capua F, Offi C, Musella M, et al. Single center experience with laparoscopic adrenalectomy on a large clinical series. BMC Surgery 201818 2. (https://doi.org/10.1186/s12893-017-0333-8)

28 Brandao LF, Autorino R, Laydner H, Haber GP, Ouzaid I, De Sio M, Perdona S, Stein RJ, Porpiglia F \& Kaouk JH. Robotic versus laparoscopic adrenalectomy: a systematic review and meta-analysis. European Urology 201465 1154-1161. (https://doi.org/10.1016/j. eururo.2013.09.021)

29 Autorino R, Bove P, De Sio M, Miano R, Micali S, Cindolo L, Greco F, Nicholas J, Fiori C, Bianchi G, et al. Open versus laparoscopic adrenalectomy for adrenocortical carcinoma: a meta-analysis of surgical and oncological outcomes. Annals of Surgical Oncology 2016 23 1195-1202. (https://doi.org/10.1245/s10434-015-4900-x)

$30 \mathrm{Hu}$ X, Yang WX, Shao YX, Dou WC, Xiong SC \& Li X. Minimally invasive versus open adrenalectomy in patients with adrenocortical carcinoma: a meta-analysis. Annals of Surgical Oncology 202027 3858-3869. (https://doi.org/10.1245/s10434-020-08454-1)

Received in final form 21 April 2021

Accepted 28 April 2021

Accepted Manuscript published online 28 April 2021 https://ec.bioscientifica.com https://doi.org/10.1530/EC-21-0062 (c) 2021 The authors Published by Bioscientifica Ltd

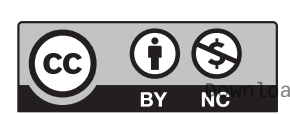

This work is licensed under a Creative Commons Attribution-NonCommercial 4.0 International License. ded from Bioscientifica com at 04/26/2023 12:51:05PM 